\title{
CAPÍtULOO V
}

Médicos y naturalistas ilustres que prestaron servicios a la causa de la independencia americana. Funda el doctor Merizalde una Cátedra de Medicina en el Colegio de San Bartolomé. - Epidemias de coqueluche y de viruela. - Providencias tomadas para contener la última. - Rapacidad de un Jefe español. Devolución del edificio y rentas del Colegio Mayor del Rosario. - Dictadura de don Juan Sámano. - El Médico Inspector del Ejército Expedicionario se radica en Santafé. - Primera Academia de Medicina que existió en esta ciudad. - Sus miembros. - Raras circunstancias que acompañaron su creación. Fin de la guerra de la independencia. Diversos nombramientos. - Libros científicos que había en el país. - Introducción de nuevos textos.

\section{De 1811 a 1819}

Los americanos, amantes de la libertad, habían iniciado la guerra de la independencia.

La historia nacional de los años de 1811 a 1824 encierra la gloriosa relación de la lucha tenaz que sostuvieron los grandes hombres de la Gran Colombia, con los aguerridos ejércitos europeos que pasaron a América, con el fin de extinguir el incendio revolucionario.

A la causa de la Patria se adhirieron con entusiasmo y decisión todos los miembros del cuerpo médico de la capital, excepción hecha de don Vicente Gil y Tejada y de algunos de los miembros de la Expedición Botánica; José Joaquín García y Pedro Lasso de la Vega prestaron servicios importantes a la santa causa de la independencia nacional, y de ellos haremos relación detallada cuando hagamos la noticia biográfica de cada uno de aquellos distinguidos parricios.

Francisco José de Caldas, el sabio, honra de su Patria y de la América; Joaquín Camacho, el ilustrado autor de la
"Memoria sobre el coto"; y don Jorge Tadeo Lozano, el Catedrático de Ciencias Naturales en el Colegio de San Bartolomé, expiaron en un patíbulo, en 1816, su amor a la libertad.

Don Manuel María Quijano, naturalista y médico distinguido, natural de Popayán, sufrió larga prisión, vejaciones y destierro de su país natal, por sus simpatías a la causa de la independencia.

El doctor José Fernández Madrid, uno de los discípulos del Padre Isla, desempeñó la Presidencia de las Provincias unidas de Nueva Granada en 1816. En servicio de tan elevado destino hizo un viaje hasta Popayán, en donde renunció el cargo presidencial.

El doctor José Félix Merizalde fundó en 1812, a sus expensas, una cátedra de medicina en el Colegio de San Bartolomé, y de su desempeño se encargó personalmente; la cátedra del Rosario continuó sus tareas bajo la dirección del doctor Benito Osorio. Ambas cátedras se suspendieron varias veces a causa de los acontecimientos políticos en 1813 y 1816, y volvieron a abrirse en 1819.

La ciudad de Bogotá sufrió en 1814 una epidemia de coqueluche, que hizo numerosas víctimas; y en 1815, una de viruela, traída por los soldados españoles que habían sitiado a Cartagena, la cual obligó a las autoridades españolas a fundar hospitales.

Don Antonio María.Casano, Gobernador de la capital, de acuerdo con los consejos de los doctores Lorenzo Bandino y Fernández de la Reguera, médicos del Ejército Expedicionario, dictó providencias de sanidad y remitió fluido vacuno a diversas partes del país.

En los hospitales fundados fueron obligados a prestar sus servicios profesionales los doctores José J. García, José Félix Merizalde, José C. Zapata y Santos González, con nombramiento de Ayudantes de Cirugía Médica; el doctor Benito Osorio, como Ayudante de Medicina, y el 
señor Domingo Hernández, como Ayudante de farmacia. En el Hospital Militar quedaron empleados el doctor Lasso de la Vega y como practicantes los señores Luis Lozano Moya y Rafael Mendoza, más tarde patriota distinguido y General de la República. Terminada la epidemia de viruela, los médicos fueron destinados a los hospitales militares, con excepción del doctor Manuel María Quijano, que fue nombrado Médico del Hospital de San Juan de Dios.

Don Pascual Enrile, segundo del Pacificador Morillo, a quien sobrepujaba como hombre de mal corazón, se llevó para España los herbarios, descripciones de plantas y pinturas del archivo de la Expedición Botánica; los trabajos científicos de Mutis, Caldas y Lozano, y las producciones literarias de otros hijos del Nuevo Reino. Los imperdonables asesinatos de Caldas, Camacho y Lozano, y la rapacidad de Enrile, dieron fin desastroso al científico instituto creado por Caballero y Góngora.

Uno de los atentados cometidos por Morillo fue la confiscación de las rentas del Colegio Mayor del Rosario y el haber destinado el edificio a prisión de Estado.

El Pacificador salió de la capital en noviembre de 1816, y aprovechando su ausencia don Domingo Burgos, Rector del Colegio del Rosario, solicitó de don Juan Sámano, con el fin de detener el asunto, remitió el expediente a Cartagena para que resolviese lo conveniente el Virrey Montalvo, que residía en aquella plaza. Montalvo ordenó la entrega del Colegio, la cual no tuvo lugar sino a fines de 1818. El doctor Benito Osorio abrió al siguiente año el curso de medicina y presentó certamen público de anatomía en medio de los azares de la guerra, en 1819.

Sámano se manifestó digno sucesor de Morillo, y con título de Gobernador Militar, mandó dictatorialmente en el centro del Virreinato. Los fusilamientos de patriotas continuaron en 1817, y Báyer, Policarpa Salabarrieta, Zabaraín, Díaz Suárez, Galiano, Arcos, Marufú, Arellano y compañeros, perecieron en el patíbulo.

El doctor Pablo Fernández de la Reguera, Inspector de los hospitales militares españoles y Director de ellos, solicitó y obtuvo licencia absoluta, el día 15 de noviembre de 1816, con el fin de radicarse en Bogotá y dedicarse al ejercicio de su profesión.
Sámano, a la sazón, verdadero Jefe del Virreinato, en cumplimiento de orden superior, dispuso que los facultativos y residentes en la capital se reuniesen cada mes, principiando el primer jueves del año de 1817, en casa del Intendente de la ciudad, con el objeto de conferenciar sobre medicina, cirugía, farmacia y química, y perfeccionar, con la discusión, los conocimientos científicos que poseyesen.

He aquí el nacimiento de la primera Academia de Medicina que existió en nuestro país, destinada a hacer progresar las ciencias naturales y médicas; y aunque duró corto tiempo, y no hizo trabajo alguno de importancia, pues sus sesiones se reducían a que uno de los miembros hiciese una conferencia sobre un punto fijado de antemano por el Director, es justicia hacer conocer los nombres de los individuos que la compusieron, y fueron:

Doctor Pablo Fernández de la Reguera, Director.

Doctor José Joaquín García, Secretario.

Doctor José C. Zapata, Secretario.

Doctor Benito Osorio, Miembro.

Doctor José Félix Merizalde, Miembro.

Doctor Santos González, Miembro.

Don Domingo Hernández, Miembro.

M.R.P. Prior fray Manuel Amaya, Miembro de la Orden de San Juan de Dios.

Prior Definidor Mariano Barroeta, Miembro de la Orden de San Juan de Dios.

Prior Definidor Agustín Uscátegui, Miembro de la Orden de San Juan de Dios.

Prior fray Agustín Silva, Miembro de la Orden de San Juan de Dios.

Admira que en la época del terror, en la que los odios de nacionalidad habían llegado al mayor grado de exaltación, la autoridad militar española se ocupase en formar una academia científica. La historia, imparcial y justiciera, reconoce este honor a Sámano, sin que él disminuya la responsabilidad que contrajo ante la posteridad, por su rencor a los americanos y por su carácter sanguinario. 
También llama la atención que nos pertenecieran a aquel cuerpocientífico dos notables médicos y hombres de ciencia, residentes en la capital. Hablamos del doctor Manuel María Quijanoy Sebastián López Ruiz, ambos acreedores por sus conocimientos médicos, a figurar en primera línea entre los miembros de la Academia.

La brillante Batalla de Boyacá, librada el 7 de agosto de 1819, selló la independencia del Nuevo Reino de Granada, y por ella terminó la dominación que España había tenido sobre nuestro país por más de tres centurias.

El Libertador y el General Santander recompensaron los servicios prestados a la Patria por los miembros del cuerpo médico. El doctor Manuel María Quijano fue nombrado Médico del Hospital de San Juan de Dios; el doctor Merizalde fue promovidodel destino de Director de Hospitales, al de Médico Mayor del Ejército y nombrado Catedrático de Medicina en San Bartolomé; el doctor Benito Osorio obtuvo nombramiento de Catedrático de Medicina; idéntica plaza ocupó el doctor JoséJoaquín García; el doctor Miguel Ibáñez fue llamado a servir destinos civiles de importancia; y los doctores José C. Zapata, Juan María Pardo, Pedro Lasso de la Vega y Francisco Quijano recibieron pruebas de aprecio y consideración de parte del Gobiemo de la República.

Hasta esa época eran pocos los libros científicos que había en la capital de la Colonia, sobre todo en ramos de medicina. Citaremos los más notables: "Instrucción para curar el dolor de costado y pulmonar"; "Instrucción para curar las calenturas conocidas con el nombre de tabardillo", por Píquer; "Terapéutica", por Alibert; "Fisiología", por Boherarvé, y las obras de Hipócrates, Sydenaham, Hoffman y Goster. Con la libertad de introducción de libros científicos no tardaron en venir al país, introducidos por don Juan Manuel Arrubla, diccionarios modernos de ciencias médicas, las obras de Andral, las de Broussais, y diversas memorias y monografías científicas, en las cuales bebieron con entusiasmo la ciencia nuestros viejos profesores, para transmitirla en la cátedra y en la clínica a sus discípulos, y para emplearla prácticamente en servicio de la sociedad, en cuyo seno les tocó vivir. 